\title{
Does metabolic rate and evaporative water loss reflect differences in migratory strategy in sexually dimorphic hoverflies?
}

\author{
Sean Tomlinson ${ }^{\mathrm{a}, \mathrm{b}, *}$, Myles H.M. Menz ${ }^{\mathrm{c}}$ \\ a School of Animal Biology, The University of Western Australia, Crawley 6009, WA, Australia \\ ${ }^{\mathrm{b}}$ Kings Park Botanic Gardens, The Botanic Gardens and Parks Authority, West Perth 6005, WA, Australia \\ c Institute of Ecology and Evolution, University of Bern, Baltzerstrasse 6, 3012 Bern, Switzerland
}

Editor: T.P. Mommsen

Keywords:

Episyrphus balteatus

Eristalis tenax

Syrphidae

Temperature

Evaporative water loss

Metabolic rate

Partial migration

Pollinator

\begin{abstract}
A B S T R A C T
A typical explanation for ecologically stable strategies that apply to only a proportion of a population, is bet hedging, where increased reproductive success offsets reduced reproductive rate. One such is partial migration, where only a proportion of a population moves seasonally to avoid inclement climatic conditions. Bet hedging may overlook unseen costs to maintain broad physiological resilience, implied by encountering a breadth of environmental conditions. We investigated the physiological correlates of partial migration by measuring standard metabolic rates, and rates of evaporative water loss, and then estimating upper and lower thermal tolerance in males and females of two hoverfly species, Episyrphus balteatus and Eristalis tenax. In central Europe, females of these species may either migrate or overwinter, whereas males may migrate south to the Mediterranean, but have not been found overwintering. Both species were sexually dimorphic; female Ep. balteatus were lighter than males, but female Er. tenax were heavier than males. While allometrically- corrected metabolic rate in both species increased with temperature, the most parsimonious models included no sex-specific differences in metabolic rate for either species. Evaporative water loss of both species also increased with temperature, but was higher for females of both species than males. Assuming that resting metabolism is congruent with the activity requirements of migration, highly consistent thermal tolerance and metabolic rate suggests that any given fly could migrate, although water loss patterns suggest that females may be less well-adapted to Mediterranean climates. We infer that partial migration probably results from the imperatives of their reproductive strategies.
\end{abstract}

\section{Introduction}

The basic premise of macrophysiology is that animals can only persist where they can tolerate the local climatic conditions and capture enough resources to maintain themselves, grow and reproduce (Chown et al., 2004; Chown and Gaston, 2008). Outside the stable climatic conditions of the tropics, however, few ecosystems are perennially suitable for many taxa, and seasonality imparts predictable, cyclical challenges. These challenges may be especially relevant to the ecological energetics of ectotherms due to their tight linkages between environmental conditions (particularly temperature), physiological efficiency and subsequent energetic demand and supply (Buckley et al., 2012).

Climates at the latitudinal extremes tend to be relatively invariable, either with consistent benign conditions to which physiological responses of ectotherms can become tightly adapted, such as the tropics (Logan et al., 2013), or nearly perennially hostile, such as the arctic and Antarctic (Klok and Chown, 1997). Temperate climates, however, show predictable patterns of seasonal variability (Chown and

\footnotetext{
* Corresponding author at: Science Directorate, Kings Park \& Botanic Gardens, Fraser Avenue, West Perth WA 6005, Australia. Tel.: +61 427978391.

E-mail address: sean.tomlinson@bgpa.wa.gov.au (S. Tomlinson).
}

Terblanche, 2006), where periods of warmth and high ecosystem productivity are interspersed with comparable or longer periods of suboptimal climate. In climates like these, many taxa have evolved life history patterns (such as emergence phenology (Waldbauer, 1978; Brooks, 1988; Danforth, 1999; Hodgson et al., 2011)) or behavioural responses (such as migration (Dingle, 2014; Chapman et al., 2011)), which are thought to buffer species against these challenges. There is evidence that seasonal responses of insects coincide broadly with their energetics and thermal tolerance thresholds (Schmidt-Nielsen, 1983; Withers, 1992; Chown and Nicholson, 2004), and a substantial literature on the energetic drivers of migration, coupled with ecosystem productivity and reproductive patterns in vertebrates (e.g., Klaasen (1996), Bowlin et al. (2005), Cochran and Wikelski (2005), Marra et al. (2005), and Zera and Brisson (2012)). However, the ecological energetics of migration has been much less explored with invertebrates (Urquhart and Urquhart, 1978; Nielsen, 2009; Chapman et al., 2011).

Partial migration, where part of the population overwinters in the summer habitat while part of the population migrates, is a widespread phenomenon in migratory species (Chapman et al., 2011). The mechanisms supporting partial migration typically include ecological factors (Ketterson and Nolan, 1976; Gauthreaux, 1982; Chapman et al., 2011; Skov et al., 2011), and the explanations of the pattern typically revolves 
around 'bet hedging', where the reduced reproductive rate resulting from one strategy is offset against the likelihood of increased reproductive success (Danforth, 1999; Hopper, 1999). Analogous to the systems described by Cohen (1966), we would assume that females would only overwinter to increase their reproductive success if pregnant and should otherwise migrate to increase their chances of survival to the next breeding season (assuming the individual as a maximising agent, critically reviewed in this context by Grafen (1999). Ideally, these strategies may alternate according to some cycle that offsets the costs of overwintering. Thus, females should remain resilient to a breadth of physiological conditions, and different energy and water budgets, or should incorporate the costs of up-regulating these tolerances into the 'bet hedging' strategy. Alternatively, males should remain more physiologically specialised, with a lesser investment in reproduction and no need to offset reproductive rate against success, and predictable annual migration. However, there have been relatively few studies investigating physiological variation in migratory tendency (but see Bevan et al (1994), Bevan et al. (1995), Bowlin et al. (2005), Cochran and Wikelski (2005), Gillis et al. (2008) and Nilsson et al. (2011)). With regard to insect physiology, the previous literature has focused on the oogenesis-flight syndrome, the trade-off between migratory ability and development of the reproductive organs (Johnson, 1969; Gatehouse and Zhang, 1995; Dingle, 2014; Zera and Harshman, 2001; Attisano et al., 2013) For example, resident female milkweed bugs (Oncopeltus fasciatus) typically have higher levels of oosorption compared to migrants (Attisano et al., 2013). By extension, where a partial migration strategy differs between sexes, then the physiological drivers of migration may differ between the sexes (Gatehouse and Zhang, 1995). However, the direction of the differences that might be expected will be dependent upon the trait in question, and the specific selection pressures applied by different migration strategies. We chose to investigate aspects of the energy and water budget and also how these traits may respond to temperature since these ecological aspects differ markedly between seasons and migration destinations. While the aspects of thermal tolerance may be predictable, where non-migrants might be hardier to lower temperatures, aspects of metabolic rate and EWL are difficult to predict, where high flight requirements may imply higher resting metabolism due to higher maintenance requirements (Marden, 2000; Darveau et al., 2002) and endurance, or may imply greater efficiency to reduce costs of transport and reduce metabolic rate (Lehmann, 2001; Niven and Scharlemann, 2005). Patterns of EWL are more complicated still, where high rates of loss might also be offset by high rates of metabolic water production (Woods and Smith, 2010) and a liquid diet.

Hoverflies (Diptera: Syrphidae) are a diverse family, comprising approximately 6000 species worldwide (Marshall, 2012). In temperate climates, hoverfly species overwinter as larvae, pupae or adults (Schneider, 1948; Dušek and Láska, 1974; Sarthou et al., 2005). Alternatively, in Europe, some hoverfly species are partially migratory, where part of the population overwinters, while the rest migrate south to milder climates for the winter, often in large numbers (e.g., Aubert et al. (1976), Aubert and Goeldlin de Tiefenau (1981), Gatter and Schmid (1990) and Nielsen (2009)). Migrating swarms include both males and fertilised females with undeveloped reproductive systems (Rotheray and Gilbert, 2011). In species that overwinter as adults, overwintering individuals are almost exclusively fertilised females in facultative reproductive diapause (Rotheray and Gilbert, 2011). Adult hoverflies have been shown to have poor cold-hardiness (Hart and Bale, 1997; Hart et al., 1997) but are thought to be able to overwinter by exploiting refugia such as buildings or vegetation (Hondelmann and Poehling, 2007; Rotheray and Gilbert, 2011; Speight, 2012). Nonetheless, overwintering syrphids have been observed to be active at ambient temperatures as low as $7{ }^{\circ} \mathrm{C}-8^{\circ} \mathrm{C}$ (Gilbert, 1985 ; Hondelmann and Poehling, 2007). Intraspecific differences in ecology and lifestyle between sexes have frequently been shown to have physiological correlates in metabolic rates (Tanaka and Ito, 1982; Watson and Lighton,
1994; Rogowitz and Chappell, 2000; Shillington and Peterson, 2002; Shillington, 2005; Tomlinson and Phillips, 2015), and although these have yet to be associated with migratory strategies, many of the ecological correlates of high metabolic rate, including aerial lifestyle are relevant to migration (Lighton and Fielden, 1995; Reinhold, 1999; Chown et al., 2007; Irlich et al., 2009).

In this study, we compared the thermal tolerance and resting metabolic physiology between the sexes of two common migratory hoverfly species in Europe, Episyrphus balteatus (de Geer, Diptera: Syrphidae: Syrphinae) and Eristalis tenax (L., Diptera: Syrphidae: Eristalinae). Both are widespread taxa, with a worldwide distribution (Speight, 2012). In Europe, Ep. balteatus and Er. tenax are partially migratory, where some individuals (both males and females) migrate south in large numbers in the autumn (e.g., Aubert et al. (1976), Aubert and Goeldlin de Tiefenau (1981) and Gatter and Schmid (1990)), while some females overwinter as adults in the summer quarters (Sarthou et al., 2005; Hondelmann and Poehling, 2007). Consequently, we hypothesised that females will have lower minimum thermal tolerance thresholds than males, as females may either overwinter or migrate south to warmer climes, whereas males tend not to overwinter (e.g., Dušek and Láska (1974), Hart and Bale (1997) and Hondelmann and Poehling (2007)). Given that both sexes experience similar summer conditions, the upper thermal tolerance thresholds are expected to be similar for both sexes.

Evidence has been accumulating that metabolic rate and evaporative water loss (EWL) are related responses (Zachariassen et al., 1987; Klok and Chown, 1997; Woods and Smith, 2010; Groenewald et al., 2013), and the calculation of water use efficiency (WUE) has provided some insights into thermal physiology of insects (Tomlinson and Phillips, 2015). Patterns of EWL have not previously been shown to differ between sexes (Willmer, 1988; Terblanche et al., 2006; Parkash et al., 2008; Tomlinson and Phillips, 2015), and patterns of WUE are most often related to patterns of metabolic rate (Willmer, 1988; Zachariassen, 1996), suggesting that WUE may follow similar patterns of thermal tolerance to metabolic rate.

\section{Methods}

\subsection{Animal collection}

Forty Ep. balteatus and 30 Er. tenax were collected in an even partition of sexes by sweep netting from ruderal meadows around the city of Bern, Switzerland (46 $\left.56^{\prime} 49.4^{\prime \prime} \mathrm{N}, 7^{\circ} 26^{\prime} 35.9^{\prime \prime E}\right)$ during the boreal summer (late July-early August). Prior to respirometry trials, the flies were kept in laboratory rearing cages at room temperature and photoperiod with pollen pack, crystalline sucrose, and water available ad libitum. No flies were maintained in this way for more than 3 days prior to measurement. Respirometry trials were begun early in the day, and the flies were assumed to be post-absorptive because they were deprived of food overnight and were given no opportunity to feed prior to introduction to the respirometer.

\subsection{Respirometry trials}

Carbon dioxide production $\left(\mathrm{VCO}_{2}\right)$ was measured as a proxy of standard metabolic rate (SMR) of both sexes using flow-through respirometry after Withers (2001), Tomlinson and Phillips (2012) and Tomlinson and Phillips (2015). We are confident in reporting SMR of these flies since they were post-absorptive and the respirometry outputs suggested that their behaviour in a darkened incubator was at rest (see Supplementary Material). Body temperature $\left(T_{\mathrm{b}}\right)$ in the metabolic chamber is assumed to be nearly equal to $T_{\mathrm{a}}$ of exposure.

Experimental temperature $\left(T_{\mathrm{a}}\right)$ was maintained to within $\pm 0.05^{\circ} \mathrm{C}$ in a Sanyo MIR-253 (SANYO Electric Biomedical Co., Ltd., Osaka, Japan) incubator at nominal temperatures of $5{ }^{\circ} \mathrm{C}, 15^{\circ} \mathrm{C}, 25^{\circ} \mathrm{C}, 35^{\circ} \mathrm{C}$ and $40{ }^{\circ} \mathrm{C}$. These temperatures were selected to provide a broad range 
of temperatures that flies may encounter whilst overwintering in central Europe, and in Mediterranean environments, to describe differences in the thermal performance curve that may correlate with different migration strategies between the sexes. While the lowest temperature is colder than the lower activity limits observed in the field by Gilbert (1985) and should represent constraints on their capacity to forage, our lower temperatures did not approach the natural extremes that inactive flies may encounter and endure. The experimental regime should, however, encompass the ecological tolerance of these flies. Precise temperatures were measured throughout each respirometry trial using DS1921-G iButtons (Maxim Integrated, San Jose, California, USA).

A dual-channel flow-through respirometry system was constructed using compressed air controlled at $50 \mathrm{~mL} \mathrm{~min}^{-1}$ (ATPD) by two Aarlborg DFC-17 mass flow controllers (Aarlborg, USA), passed through two $5 \mathrm{~mL}$ glass chambers containing a bed of granulated soda lime ( $\mathrm{CaOH}$, Sigma-Aldrich Chemicals, Australia) separated from a $1 \mathrm{~mL}$ headspace containing the flies by a plug of cotton wool. Excurrent air was dried with Drierite (anhydrous calcium sulphate, W.A. Hammond Company Ltd, USA) ahead of two Qubit S151 infrared $\mathrm{CO}_{2}$ analysers (Qubit systems Inc, USA). Although Drierite has an established affinity for $\mathrm{CO}_{2}$ and has been suggested to increase washout times, White et al. (2006) demonstrated that Drierite is an appropriate desiccant to use for steady-state metabolic measurements such as those undertaken in this study. The gas analysers were calibrated and checked for linearity using a three-point calibration with $\mathrm{N}_{2}$ gas ( $0 \mathrm{ppm}$ ), air (350 ppm) and a calibration gas mix (1500 ppm; BOC Gases, Australia). Analogue data signals from all equipment were interfaced to a computer via a DataQ 710 data acquisition board (DataQ Instruments, USA) collected every $10 \mathrm{~s}$ using a custom-written Visual Basic version 6.0 data acquisition program. Trials were run for $45 \mathrm{~min}$, with a minimum $30 \mathrm{~min}$ baseline always run before and after the respirometry trials. Body mass was measured before and after trials using a Mettler-Toledo AT200 electronic balance (correct to $10^{-4} \mathrm{~g}$ ), and the difference was recorded as a gravimetric measure of evaporative water loss (EWL). Metabolic traces were analysed by a custom-written Visual Basic program to determine the minimum 20-min average for $\mathrm{VCO}_{2}$ at each $T_{\mathrm{a}}$.

\subsection{Statistical analysis}

In order to account for the effects of body mass differences that might be obscuring inter- and intraspecific patterns of physiological adaptation (Schmidt-Nielsen, 1983; Withers, 1992), we tested for differences in body mass between sexes, between and within species, and between and within temperature trials using ANOVA. Where significant differences in mass were found, metabolic rates were scaled by body mass $^{0.75}$ (Chown et al., 2007), while EWL was scaled by body mass ${ }^{0.67}$ (Edney, 1977; Chown et al., 1998). Metabolic rates at $25^{\circ} \mathrm{C}$ were compared to their allometric expectations with Student's $t$-tests to test for a difference between the observed rate and that calculated based on body mass, both for the complete allometry reported by Chown et al. (2007), and for the Diptera reported by Terblanche et al. (2004).

The thermal performance curves of ectotherms are unimodal, humped functions defined by distinct reductions in performance at upper and lower tolerance thresholds (Angilletta, 2006; Kovac et al., 2007). Therefore, we used a non-linear curve fitting approach to estimate physiological responses to $T_{\mathrm{a}}$. The effects of species and sex on the various combinations of coefficients were modelled using nonlinear least-squares regression (nls), and the models were compared following an information criterion approach (Burnham and Anderson, 2002) using the AICcmodavg package (Mazerolle, 2013) for R. The most parsimonious curves reported here are described by a combination of shared and unique coefficients. Where no discrimination between sexes was found we report the convergent equation.

The response of $\mathrm{VCO}_{2}$ to $T_{\mathrm{a}}$ was estimated using a biexponential function reported by Tomlinson and Phillips (2015), modified by the addition of a lower temperature deviation analogous to those described by Kovac et al. (2007); Eq. (1C). The resulting function was

$\mathrm{VCO}_{2}=y_{0} \times\left(e^{k \times \mathrm{T}_{\mathrm{a}}}-e^{l-\mathrm{T}_{\mathrm{a}}}-e^{\mathrm{T}_{\mathrm{a}}-h}\right)$

where $y_{0}$ is the intercept of the curve at $0{ }^{\circ} \mathrm{C}, k$ is the scaling exponent and $l$ and $h$ represent lower and upper thermal fitting constraints, respectively. The addition of a lower constraint complicates the biological interpretation of the fit by comparison to that made by Tomlinson and Phillips (2015) because tolerance thresholds, $T_{\mathrm{ld}}$ and $T_{\text {hd }}$, are no longer parameters of the primary function. The temperature of peak response ( $T_{\mathrm{MMR}}$, analogous to $\mathrm{M}_{\mathrm{T}} \mathrm{R}$; Tomlinson and Phillips (2012), Tomlinson and Phillips (2015)) was estimated by calculating the first order derivative using the numDeriv package (Gilbert and Varadhan, 2012) and solving using the 'uniroot' function after Brent (1973). Two points of deviation analogous to $T_{d}$ reported by Tomlinson and Phillips (2015) were estimated by solving the second order derivative to give $T_{\mathrm{ld}}$, the lower point of deviation, and $T_{\text {hd }}$, the upper point of deviation. Where these fits could not be resolved for a species, we applied the biexponential fit described by Tomlinson and Phillips (2015) to estimate as many points of thermal tolerance as our data permitted.

The effects of $T_{\mathrm{a}}$ on EWL were modelled using an exponential model:

$\mathrm{EWL}=y_{0} \times e^{k \times \mathrm{T}_{\mathrm{a}}}$

where $y_{0}$ is the intercept of the curve at $0{ }^{\circ} \mathrm{C}$ and $k$ is the scaling exponent. Water use efficiency (WUE) was calculated by the division of metabolic rate (to approximate metabolic water production) by EWL following Zachariassen et al. (1987) and Klok and Chown (1998), and described by linear regression between the identified limits of thermal tolerance where the intercept $b$ estimates WUE where $T_{\mathrm{a}}=0{ }^{\circ} \mathrm{C}$, and the slope $m$ estimates the rate of change of WUE with $T_{\mathrm{a}}$. Statistical analyses were performed in $\mathrm{R}$ version 3.0.3 (R Core Team, 2015). Data are presented as mean \pm SE.

\section{Results}

\subsection{Inter- and intraspecific patterns of body mass}

Episyrphus balteatus $(24.9 \pm 2.21 \mathrm{mg})$ weighed less than Er. tenax $(116.4 \pm 13.57 \mathrm{mg})$, in keeping with their smaller size $\left(F_{1,49}=1131\right.$, $p<0.001)$. Within both Ep. balteatus $\left(F_{1,30}=6.43, p=0.017\right)$ and Er. tenax $\left(F_{1,19}=6.43, p<0.001\right)$, there were sexual differences in body mass. In Ep. balteatus females $(20.1 \pm 1.57 \mathrm{mg})$ weighed less than males $(29.6 \pm 2.35 \mathrm{mg})$, but in Er. tenax females $(144.8 \pm 5.94 \mathrm{mg})$ were heavier than males $(88.1 \pm 9.06 \mathrm{mg})$. As a result of these divergent patterns in body mass, comparisons of metabolic rate and evaporative water loss have been made using allometrically corrected values.

\subsection{Effects of temperature on metabolic rate and evaporative water loss}

Metabolic rate of Ep. balteatus at $25^{\circ} \mathrm{C}\left(3.57 \pm 0.51 \mathrm{mLCO}_{2} \mathrm{~g}^{-1} \mathrm{~h}^{-1}\right)$ was $167.4 \%$ of that expected for an insect of its size $\left(2.11 \mathrm{mLCO}_{2} \mathrm{~g}^{-1} \mathrm{~h}^{-1}\right)$, 1), while Er. tenax at $25^{\circ} \mathrm{C}\left(5.21 \pm 0.81 \mathrm{mLCO}_{2} \mathrm{~g}^{-1} \mathrm{~h}^{-1}\right)$ was $330.6 \%$ of that expected for all insects (1.60 $\mathrm{mLCO}_{2} \mathrm{~g}^{-1} \mathrm{~h}^{-1}$; Chown et al. (2007)). While both species fell within the range of other values in the dipteran relationship reported by Terblanche et al. (2004), both Ep. balteatus (expected $=2.13 \mathrm{mLCO}_{2} \mathrm{~g}^{-1} \mathrm{~h}^{-1} ; t_{7}=21.1, p=0.0171$ ) and $E r$. tenax (expected $=1.67 \mathrm{mLCO}_{2} \mathrm{~g}^{-1} \mathrm{~h}^{-1} ; t_{5}=14.7, p=0.0272$ ) had significantly higher metabolic rates at $25^{\circ} \mathrm{C}$ than allometric predictions for Diptera, although none of the taxa that informed these expectations were syrphids (Addo-Bediako et al., 2002; Terblanche et al., 2004). We infer that perhaps the Syrphidae generally have higher resting metabolic rates than expected by allometric scaling due to aspects of the biology that have previously been associated with high residuals in other groups, including an aerial lifestyle (Reinhold, 1999) and a nectarivorous 
diet (McNab, 1988; Nagy et al., 1999). However, a greater number of syrphid species need to be added to the data set to substantiate this (Felsenstein, 1985; Garland and Adolph, 1994).

Resting metabolic rate in both species increased non-linearly with increasing $T_{\mathrm{a}}$ (Fig. 1), and our three-part exponential fit found deviations from a pure exponential model. However, the estimated upper $\left(T_{\text {hd }}\right)$ and lower $\left(T_{\mathrm{ld}}\right)$ thermal deviations occur very close to or beyond the limits of the data set measured (Table 1). It was not possible to fit a unique three-part exponential function for Ep. balteatus because the lower thermal deviation $\left(T_{\mathrm{ld}}\right)$ could not be resolved from our data. This suggests that it is much lower than the lower metabolic constraint of Er. tenax, for which we could resolve a unique three-part exponential performance function. Similarly, Ep. balteatus was slightly more thermally tolerant at the upper extreme than Er. tenax (Fig. 1). The most parsimonious intraspecific models included no significant effects of sex on any of the coefficients for Ep. balteatus or Er. tenax (Table 1). The $T_{\mathrm{MMR}}$ of Ep. balteatus resolved at $39.4{ }^{\circ} \mathrm{C} \pm 0.05{ }^{\circ} \mathrm{C}$ while Er. tenax resolved at $38.6{ }^{\circ} \mathrm{C} \pm 0.05^{\circ} \mathrm{C}$. The $T_{\text {hd }}$ of Ep. balteatus resolved at $38.7^{\circ} \mathrm{C} \pm 0.99{ }^{\circ} \mathrm{C}$ while Er. tenax resolved at $35.5^{\circ} \mathrm{C} \pm 0.05{ }^{\circ} \mathrm{C}$. The $T_{\text {ld }}$ of Ep. balteatus could not be resolved, but Er. tenax resolved at $9.4{ }^{\circ} \mathrm{C} \pm 0.05^{\circ} \mathrm{C}$ (Table 2).

EWL of both species increased exponentially with increasing $T_{\mathrm{a}}$ (Fig. 1), with the most parsimonious model of species-sex interactions including a consistent intercept $y_{0}$ for all species-sex combinations, but unique temperature scaling exponents $k$ (Tables 1 and 2). The only significant effect on WUE was the species- $T_{\mathrm{a}}$ interaction $\left(F_{4,45}=\right.$ $6.19, p<0.001$ ), and the most parsimonious linear model included unique slopes $(m)$ and intercepts $(b)$ in the linear models of WUE for both species (Table 2).

\section{Discussion}

We compared the thermal performance between sexes of two species of syrphid flies that are partial migrants in Europe (e.g., Aubert
Table 1

Akaike Information Criterion comparison (AICc) of the unique parameter permutations of the thermal performance curve of $(A)$ interspecific metabolic rate comparisons (unique parameters are denoted by [sp]) and (B) interspecific evaporative water loss comparisons (unique parameters are denoted by [fac]). [sp] indicates the partitioning of the coefficient on the basis of species, while [fac] indicates the partitioning of the coefficient on the basis of unique species $\times$ sex combinations.

\begin{tabular}{|c|c|c|c|c|c|}
\hline Model & $\mathrm{k}$ & AICc & $\triangle \mathrm{AICc}$ & $\mathrm{w}_{\mathrm{i}}$ & Log Likelihood \\
\hline \multicolumn{6}{|l|}{$(A)$} \\
\hline$y_{0}[\mathrm{sp}] \times\left(e^{k[\mathrm{sp}] \times \mathrm{T}_{\mathrm{a}}}-e^{l-\mathrm{T}_{\mathrm{a}}}-e^{\mathrm{T}_{\mathrm{a}}-h}\right)$ & 5 & 208.7 & 0.00 & 0.63 & -96.4 \\
\hline$y_{0}[\mathrm{sp}] \times\left(e^{k[\mathrm{sp}] \times \mathrm{T}_{\mathrm{a}}}-e^{l-\mathrm{T}_{\mathrm{a}}}-e^{\mathrm{T}_{\mathrm{a}}-h[\mathrm{sp}]}\right)$ & 8 & 211.2 & 2.44 & 0.18 & -96.3 \\
\hline$y_{0}[\mathrm{sp}] \times\left(e^{k \times T_{\mathrm{a}}}-e^{l-\mathrm{T}_{\mathrm{a}}}-e^{\mathrm{T}_{\mathrm{a}}-h}\right)$ & 6 & 211.3 & 2.54 & 0.18 & -98.9 \\
\hline$y_{0} \times\left(e^{k[\mathrm{sp}] \times \mathrm{T}_{\mathrm{a}}}-e^{l-\mathrm{T}_{\mathrm{a}}}-e^{\mathrm{T}_{\mathrm{a}}-h}\right)$ & 6 & 216.3 & 7.57 & 0.01 & -101.4 \\
\hline$y_{0} \times\left(e^{k \times T_{a}}-e^{l-T_{a}}-e^{T_{a}-h}\right)$ & 5 & 227.6 & 18.89 & 0.00 & -108.3 \\
\hline \multicolumn{6}{|l|}{ (B) } \\
\hline$y_{0}[\mathrm{fac}] \times e^{k[\mathrm{fac}] \times \mathrm{T}_{\mathrm{a}}}$ & 9 & -502.2 & 0.00 & 0.92 & 261.2 \\
\hline$y_{0} \times e^{k[\mathrm{fac}] \times \mathrm{T}_{\mathrm{a}}}$ & 6 & -496.9 & 5.35 & 0.06 & 254.9 \\
\hline$y_{0}[\mathrm{fac}] \times e^{k \times \mathrm{T}_{a}}$ & 6 & -494.3 & 7.97 & 0.02 & 253.6 \\
\hline$y_{0} \times e^{k \times \mathrm{T}_{\mathrm{a}}}$ & 3 & -473.4 & 28.8 & 0.00 & 239.9 \\
\hline
\end{tabular}

et al. (1976), Aubert and Goeldlin de Tiefenau (1981) and Gatter and Schmid (1990)). Both species had higher resting metabolic rates than expected from allometric patterns in other Diptera (see Chown et al. (2007) and Terblanche et al. (2004)). The WUE of Ep. balteatus correlates with mesic species described by Zachariassen et al. (1987) and Klok and Chown (1997), but the position of Er. tenax is more equivocal and may suggest greater tolerance to aridity. Although the thermal performance profiles of metabolic rate, indicative of thermal tolerance, were substantially different between the species, these differences are largely associated with lower thermal tolerance, rather than tolerance to high temperature, as has been explored using these statistical approaches previously (Kovac et al., 2007; Tomlinson and Phillips, 2012; Kovac et al., 2014; Tomlinson and Phillips, 2015). This is consistent

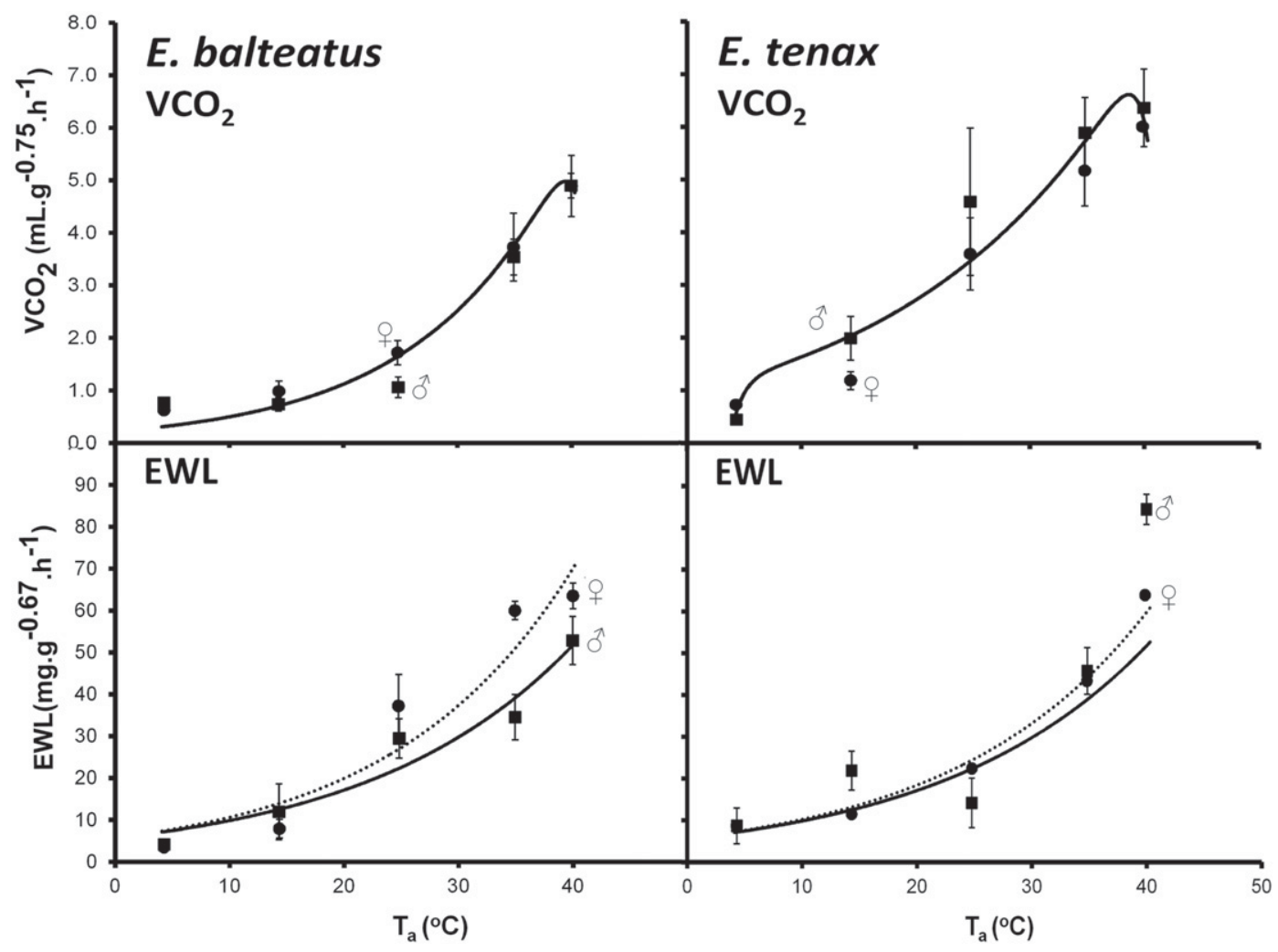

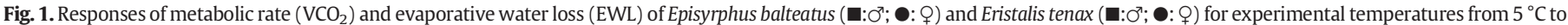
$40^{\circ} \mathrm{C}$. Data are presented as means $\pm 1 \mathrm{SEM}$ of values standardised by allometric scaling of individual body mass (see methods for details). The black line in the VCO $\mathrm{Panel}$ represents the convergent fit for both sexes. The black line in the EWL panel represents the fit for males, and the dashed line represents the fit for females. 
Table 2

Coefficients of the most parsimonious model of effects of species and sex on thermal performance of metabolic rate $\left(\mathrm{VCO}_{2}\right)$ and evaporative water loss (EWL), where $y_{0}$ is the $y$-intercept, $k$ is the scaling exponent and $T_{\mathrm{ld}}$ and $T_{\mathrm{hd}}$ the lower and upper temperatures of divergence from the base exponential respectively, and water use efficiency (WUE), where $b$ is the $y$-intercept and $m$ is the rate of change with $T_{\mathrm{a}}$. Errors are the standard error of the fitted coefficients. The peak $\mathrm{VCO}_{2}$ is estimated from the first order derivative at $T_{\mathrm{MmR}}$, and errors represent the precision of estimation for both.

\begin{tabular}{|c|c|c|c|c|c|c|c|c|c|c|}
\hline \multirow[t]{2}{*}{ Species } & & \multicolumn{5}{|l|}{$\mathrm{VCO}_{2}$} & \multicolumn{2}{|l|}{ EWL } & \multicolumn{2}{|l|}{ WUE } \\
\hline & & $y_{0}$ & $k$ & $T_{\text {hd }}$ & $T_{\text {ld }}$ & $T_{\mathrm{MMR}}$ & $y_{0}$ & $k$ & $m$ & $b$ \\
\hline Episyrphus balteatus & $\begin{array}{l}0^{7} \\
\text { Q }\end{array}$ & $0.22 \pm 0.07$ & $0.08 \pm 0.01$ & $38.7 \pm 0.99$ & - & $39.4 \pm 0.05$ & $0.06 \pm 0.001$ & $\begin{array}{l}0.06 \pm 0.47 \\
0.06 \pm 0.63\end{array}$ & $-0.003 \pm 0.0012$ & $0.21 \pm 0.032$ \\
\hline Eristalis tenax & $\begin{array}{l}0^{\pi} \\
q\end{array}$ & $0.98 \pm 0.44$ & $0.05 \pm 0.01$ & $35.5 \pm 0.05$ & $9.4 \pm 0.05$ & $38.6 \pm 0.05$ & & $\begin{array}{l}0.06 \pm 0.62 \\
0.06 \pm 0.51\end{array}$ & $0.0009 \pm 0.0012$ & $0.11 \pm 0.032$ \\
\hline
\end{tabular}

with the ecology of the species, where both species experience similar summer conditions, but Ep. balteatus activity can be observed in the field at very low temperatures (Gilbert, 1985).

\subsection{Thermal sensitivity}

Our data showed the distinctly humped thermal performance curves that have been found previously for ectotherms (Angilletta, 2006; Kovac et al., 2007; Tomlinson and Phillips, 2015). The thermal performance function that we describe here is slightly more informative than previous approaches, in that it allows the estimation of both upper and lower tolerance thresholds, compared to the focus on high thermal tolerance of previous studies (Tomlinson and Phillips, 2015). Furthermore, the non-linear regression approach is a more theoretically rooted approach than the generalised additive models reported by Kovac et al. (2007), which are more referential to the data, and hence more prone to over-fitting (Wood, 2008). What we found as a result is that, while there are substantial differences in the thermal performance functions between the two species, these differences largely relate to the tolerance to low temperatures $\left(T_{\mathrm{ld}}\right)$, and probably would not be detectable on the basis of upper thermal tolerance ( $T_{\mathrm{hd}}$ or $\left.T_{\mathrm{MMR}}\right)$. In the context of the ecology and evolution of these flies, this makes sense, since cold temperatures at high latitudes are probably a more proximal constraint on insects in Europe than high thermal tolerance, especially in the context of heavy glaciation during the last glacial maximum (Florineth and Schluchter, 1998). However, we encourage a broader, phylogenetically informed study of these thermal tolerance thresholds to better understand their ecological and evolutionary correlates.

We could not resolve $T_{\mathrm{ld}}$ for Ep. balteatus from our data. However, this implies that the lower threshold was colder than our measurement limits and had not yet begun to influence the $\mathrm{VCO}_{2}$ of Ep. balteatus. We were able to generate more reliable fits for Er. tenax and estimated $T_{\mathrm{ld}}$ at approximately $9.5{ }^{\circ} \mathrm{C}$. A tolerance threshold at $9.5{ }^{\circ} \mathrm{C}$ is congruent with the prior reports of observed activity of these species at low temperatures in the field on sunny days during winter (Gilbert, 1985; Hondelmann and Poehling, 2007).

We had hypothesised that females would be more tolerant of cold temperatures than males, but that there would be no differences in upper thermal tolerance thresholds. While the upper thresholds of males and females were indistinguishable, we also found no evidence of differences at low temperatures, suggestive that any individual from the population is physiologically capable of tolerating overwintering conditions, or of migrating and tolerating warmer climates further south. While some studies of intraspecific dimorphism in thermal tolerance of insects found that thermal tolerance may also differ between sexes (Folk et al., 2006; Pappas et al., 2007), our findings agree with others that have found no differences in tolerance thresholds, (Jensen et al., 2007; Nyamukondiwa and Terblanche, 2009; Stotter and Terblanche, 2009; Tomlinson and Phillips, 2015). While this implies that both sexes naturally inhabit similar thermal environments (Nyamukondiwa and Terblanche, 2009), Tomlinson and Phillips (2015) interpreted this as evidence of powerful selection pressure on females during their relatively short exposure to the challenges of high environmental $T_{\mathrm{a}}$ that they would otherwise not experience throughout the rest of their life cycle.
Such an argument seems less plausible here, since both males and females are surface dwelling, but males tend to avoid seasonally cold climates, while females may overwinter (e.g., Hondelmann and Poehling (2007)). The most parsimonious conclusion from our data is that the partial migration strategies of Ep. balteatus and Er. tenax have not placed differential selective pressures on the thermal tolerances and energetic requirements at rest, of the two sexes.

\subsection{Differences in metabolic rate between the sexes}

Previous studies have found striking and substantial differences between the metabolic rates of males and females in some taxa (Tanaka and Ito, 1982; Watson and Lighton, 1994; Rogowitz and Chappell, 2000; Shillington and Peterson, 2002; Shillington, 2005; Tomlinson and Phillips, 2015). None of these studies related sexual dimorphism of metabolic physiology to thermal tolerance, however. The most parsimonious explanation in the literature relates to differences in the energetic investment in reproduction, related to mate searching (Shillington and Peterson, 2002; Shillington, 2005; Tomlinson and Phillips, 2015) or male/male competition and mate guarding (Watson and Lighton, 1994; Rogowitz and Chappell, 2000). Although males of some syrphid species defend territories (Gilbert, 1985), this defence is not hugely energetic in the context of the highly energetic aerial foraging strategy of both sexes, and the established explanations of metabolic dimorphism do not seem applicable to either species studied here. Furthermore, sexual dimorphism of metabolic rates related to mating behaviour in this way have previously been correlated to differences in flight muscle mass (Radloff et al., 2003; Skandalis and Darveau, 2012; Darveau et al., 2014), a scenario that would be a plausible expectation due to the intraspecific differences in body mass that we found but should operate in opposite directions for each species. Nonetheless, this should have been accounted for by our mass scaling correction, and we found no evidence of intraspecific sex-based differences in metabolic rate. Even in situations where differences in body composition between the sexes do not result in net differences in body mass, the maintenance of highly active tissues can increase resting rates (Marden, 2000; Niven and Scharlemann, 2005). While this may not be influenced by body mass, we once again found no evidence of this in the hoverflies we studied. Our study instead joins those that have found no evidence for intraspecific variation in metabolic rates (Rajagopal and Bursell, 1966; Humphreys, 1977; Penteado and Hebling-Beraldo, 1991; Terblanche et al., 2004; Terblanche and Chown, 2007).

\subsection{Differences in EWL between the sexes}

Previously, differences in WUE have been attributed to sexual dimorphism of metabolic rate because EWL was invariant between sexes (Tomlinson and Phillips, 2015). Our data have shown the converse to be true in two syrphid species, but there are few other studies with which to compare our findings. Given that relative humidity is as powerful an effector of physiology as temperature (van Wijk, 1963; Körtner et al., 2008), and that EWL and high WUE are defining characteristics of arid-zone invertebrates (Hadley, 1970; Cloudsley-Thompson and Constantinou, 1983; Cloudsley-Thompson, 1991; Hadley et al., 1991; 
Hadley, 1994; Klok and Chown, 1998; Mason et al., 2013), the more accurate interpretation may be that males have lower EWL than females, and consequently higher WUE. However, we lack a broad enough phylogenetic and ecological context to substantiate this convincingly (Felsenstein, 1985; Garland and Adolph, 1994), and we advocate a broader study of the rates of WUE in order to understand its ecological correlates.

\section{Conclusions}

Both Ep. balteatus and Er. tenax appear to have relatively broad thermal tolerances, with good tolerance to low $T_{\mathrm{a}}$ and similar upper tolerance thresholds to those reported for many more thermophilic species (Terblanche et al., 2004; Terblanche et al., 2006; Kovac et al., 2007; Terblanche and Chown, 2007; Tomlinson and Phillips, 2012; Kovac et al., 2014). Of the two species, Ep. balteatus seems tolerant to much colder temperatures than Er. tenax. Our hypothesis of differences in thermal response and resting energetics between sexes within species was not supported, which is congruent with previous interpretations of the evolutionary bases of this dimorphism in other species (Tanaka and Ito, 1982; Watson and Lighton, 1994; Rogowitz and Chappell, 2000; Shillington and Peterson, 2002; Shillington, 2005; Tomlinson and Phillips, 2015). The invariant patterns of thermal tolerance and metabolic rate within each species estimated here from resting rates suggested that any given fly is capable of migrating or overwintering indicating that migration is likely triggered by other factors such as environmental or ecological cues. Alternatively, it has been suggested that resting physiological traits are poor correlates of flight performance (Weibel et al., 2004; Terblanche and Anderson, 2010), and differences in migration capacity could be better detected by the comparison of flight energetics. We did, however, find higher rates of EWL in females of both species than in conspecific males, which implied lower WUE. The ecological basis of these patterns may relate to increased WUE of males in response to the partial migration strategy of these species, but a study of EWL and WUE with much broader taxonomic scope is required to support this interpretation with any certainty. Finally, while this study provides insight into the metabolic rate and thermal tolerance of two migratory hoverfly species, our interpretations would be greatly expanded by investigating these differences in actively migrating and overwintering individuals.

\section{Acknowledgements}

We thank Adam Munn the loan of metabolic equipment. The custom-written programs used to collect and analyse data were modified by S.T. from originals coded by Philip Withers. During the completion of this study, S.T. was supported by Australian Research Council Linkage Grant LP110200304 (Awarded to Kingsley Dixon, Raphael Didham and Don Bradshaw). The support of Kingsley Dixon, Raphael Didham, Don Bradshaw and Wolfgang Nentwig in pursuing this research is gratefully acknowledged.

\section{References}

Addo-Bediako, A., Chown, S.L., Gaston, K.J., 2002. Metabolic cold adaptation in insects: large-scale perspective. Funct. Ecol. 16, 332-338.

Angilletta, M.J., 2006. Estimating and comparing thermal performance curves. J. Therm. Biol. 31, 541-545.

Attisano, A., Tregenza, T., Moore, A.J., Moore, P.J., 2013. Oosorption and migratory strategy of the milkweed bug, Oncopeltus fasciatus. Anim. Behav. 86, 651-657.

Aubert, J., Goeldlin de Tiefenau, P., 1981. Observations sur les migrations de Syrphides (Dipt.) dans les Alpes de Suisse occidentale. Mitt. Schweiz. Entomol. Ges. 54, 377-388.

Aubert, J., Aubert, J.-J., Goeldlin, P., 1976. Douze ans de captures systématiques de Syrphides (Diptères) au col de Bretolet (Alpes valaisannes). Mitt. Schweiz. Entomol. Ges. 49, 115-142.
Bevan, R.M., Woakes, A.J., Butler, P.J., Boyd, I.L., 1994. The use of the heart rate to estimate oxygen consumption of free-ranging black-browed albatrosses Diomedea melanophrys. J. Exp. Biol. 193, 119-137.

Bevan, R.M., Butler, P.J., Woakes, A.J., Prince, P.A., 1995. The energy expenditure of freeranging black-browed albatrosses. Philos. Trans. R. Soc. Lond. B 350, 119-131.

Bowlin, M.S., Cochran, W.W., Wikelski, M.C., 2005. Biotelemetry of New World thrushes during migration: physiology, energetics and orientation in the wild. Integr. Comp. Biol. 45, 295-304.

Brent, R., 1973. Algorithms for Minimization without Derivatives. Prentice-Hall, Englewood Cliffs, NJ.

Brooks, R.W., 1988. Systematics and phylogeny of the anthophorine bees (Hymenoptera: Anthophoridae; Anthophorini). 53. University of Kansas Science Bulletin, pp. 436-575.

Buckley, L.B., Hurlbert, A.H., Jetz, W., 2012. Broad-scale ecological implications of ectothermy and endothermy in changing environments. Glob. Ecol. Biogeogr. 21, 873-885.

Burnham, K.P., Anderson, D.R., 2002. Model Selection and Multimodel Inference: A Practical Information-Theoretic Approach. 2nd edition. Springer, New York.

Chapman, B.B., Brönmark, C., Nilsson, J.Å., Hansson, L.A., 2011. The ecology and evolution of partial migration. Oikos 120, 1764-1775.

Chown, S.L., Gaston, K.J., 2008. Macrophysiology for a changing world. Proc. R. Soc. B 275, 1469-1478.

Chown, S.L., Nicholson, S.W., 2004. Insect Physiological Ecology: Mechanisms and Patterns. Oxford University Press, Oxford.

Chown, S.L., Terblanche, J.S., 2006. Physiological diversity in insects: ecological and evolutionary contexts. Adv. Insect Physiol. 33, 50-152.

Chown, S.L., Pistorius, P.A., Scholtz, C.H., 1998. Morphological correlates of flightlessness in southern African Scarabaeinae (Coleoptera: Scarabaeidae): testing a condition of the water conservation hypothesis. Can. J. Zool. 76, 1123-1133.

Chown, S.L., Gaston, K.J., Robinson, D., 2004. Macrophysiology: large-scale patterns in physiological traits and their ecological implications. Funct. Ecol. 18, 159-167.

Chown, S.L., Marais, E., Terblanche, J.S., Klok, C.J., Lighton, J.R.B., Blackburn, T.M., 2007. Scaling of insect metabolic rate is inconsistent with the nutrient supply network model. Funct. Ecol. 21, 282-290.

Cloudsley-Thompson, J.L., 1991. Ecophysiology of Desert Arthropods and Reptiles. SpringerVerlag, Berlin.

Cloudsley-Thompson, J.L., Constantinou, C., 1983. Transpiration from forest dwelling and woodland Mygalomorphae (Araneae). Int. J. Biometeorol. 27, 69-74.

Cochran, W.W., Wikelski, M., 2005. Individual migratory tactics of New World Catharus thrushes: current knowledge and future tracking options from space. In: Marra, P., Greenberg. R. (Eds.), Birds of Two Worlds: The Ecology and Evolution of Migration. Johns Hopkins University Press.

Cohen, D., 1966. Optimizing reproduction in a randomly varying environment. J. Theor Biol. 12, 119-129.

Core Team, R., 2015. R: A language and environment for statistical computing. R Foundation for Statistical Computing, Vienna, Austria.

Danforth, B.N., 1999. Emergence dynamics and bet hedging in a desert bee, Perdita portalis. Proc. R. Soc. B 266, 1985-1994.

Darveau, C.A., Suarez, R.K., Andrews, R.D., Hochachka, P.W., 2002. Allometric cascades as a unifying principle of body mass effects on metabolism. Nature 417, 166-170.

Darveau, C.A., Billardon, F., Bélanger, K., 2014. Intraspecific variation in flight metabolic rate in the bumblebee Bombus impatiens: repeatability and functional determinants in workers and drones. J. Exp. Biol. 217, 536-544.

Dingle, H., 2014. Migration: the biology of life on the move. 2nd ed. Oxford University Press, Oxford.

Dušek, J., Láska, P., 1974. Overwintering and spring emergence of some common species of aphidophagous syrphids (Syrphidae, Diptera). Folia Facultatis Scientiarum Naturalium Universalis Purkynianae Brunensis. Biologia 43, 71-75.

Edney, E.B., 1977. Zoophysiology and Ecology 9, Water Balance in Land Arthropods. Springer-Verlag, Berlin.

Felsenstein, J., 1985. Phylogenies and the comparative method. Am. Nat. 125, 1-15.

Florineth, D., Schluchter, C., 1998. Reconstructing the Last Glacial Maximum (LGM) ice surface geometry and flowlines in the Central Swiss Alps. Eclogae Geol. Helv. 91, 391-407.

Folk, D.G., Zwollo, P., Rand, D.M., Gilchrist, G.W., 2006. Selection on knockdown performance in Drosophila melanogaster impacts thermotolerance and heat-shock response differently in females and males. J. Exp. Biol. 209, 3964-3973.

Garland, T.J., Adolph, S.C., 1994. Why not to do two-species comparative studies: limitations on inferring adaptation. Physiol. Zool. 67, 797-828.

Gatehouse, A.G, Zhang XX, 1995. Migratory potential in insects: variation in an uncertain environment. In: Drake, V.A., Gatehouse, A.G. (Eds.), Insect Migration: Tracking Resources through Space and Time. Cambridge University Press, Cambridge, pp. 193-242.

Gatter, W., Schmid, U., 1990. Wanderung der Schwebfliegen (Diptera, Syrphidae) am Randecker Maar. Spixiana Suppl. 15, 1-100.

Gauthreaux S.A.J., 1982. The ecology and evolution of avian migration systems. In: Farner, D.S., King, J.R., Parkes, K.C. (Eds.), Avian Biology. Academic Press, London, pp. 93-168.

Gilbert, F.S., 1985. Diurnal activity patterns in hoverflies (Diptera, Syrphidae). Ecol. Entomol. 10, 385-392.

Gilbert, P., Varadhan, R., 2012. numDeriv: Accurate Numerical Derivatives. R package version 2012.9-1.

Gillis, E.A., Green, D.J., Middleton, H.A., Morrissey, C.A., 2008. Life history correlates of alternative migratory strategies in American Dippers. Ecology 89, 1687-1695.

Grafen, A., 1999. Formal darwinism, the individual-as-maximizing-agent analogy and bet-hedging. Proc. R. Soc. B 266, 799-803.

Groenewald, B., Bazelet, C.S., Potter, C.P., Terblanche, J.S., 2013. Gas exchange patterns and water loss rates in the Table Mountain cockroach, Aptera fusca (Blattodea: Blaberidae). J. Exp. Biol. 2016, 3844-3853.

Hadley, N.F., 1970. Water relations of the desert scorpion Hadrurus arizonensis. J. Exp. Biol. $53,547-558$. 
Hadley, N.F., 1994. Water relations of terrestrial arthropods. Academic Press.

Hadley, N.F., Quinlan, M.C., Kennedy, M.L., 1991. Evaporative cooling in the desert cicada: thermal efficiency and water/metabolic costs. J. Exp. Biol. 159, 269-283.

Hart, A.J., Bale, J.S., 1997. Cold tolerance of the aphid predator Episyrphus balteatus (DeGeer) (Diptera, Syrphidae). Physiol. Entomol. 22, 332-338.

Hart, A.J., Bale, J.S., Fenlon, J.S., 1997. Developmental threshold, day-degree requirements and voltinism of the aphid predator Episyrphus balteatus (Diptera: Syrphidae). Ann. Appl. Biol. 130, 427-437.

Hodgson, J.A., Thomas, C.D., Oliver, T.H., Anderson, B.J., Breretom, T.M., Crone, E.E., 2011. Predicting insect phenology across space and time. Glob. Chang. Biol. 17, 1289-1300.

Hondelmann, P., Poehling, H.-M., 2007. Diapause and overwintering of the hoverfly Episyrphus balteatus. Entomol. Exp. Appl. 124, 189-200.

Hopper, K.R., 1999. Risk-spreading and bet-hedging in insect population biology. Annu. Rev. Entomol. 44, 535-560.

Humphreys, W.F., 1977. Respiration studies on Geolycosa godeffroyi (Araneae: Lycosidae) and their relationship to field estimates of metabolic heat loss. Comp. Biochem. Physiol. A 57, 555-563.

Irlich, U.M., Terblanche, J.S., Blackburn, T.M., Chown, S.L., 2009. Insect rate-temperature relationships: environmental variation and the metabolic theory of ecology. Am. Nat. 174, 819-835.

Jensen, D., Overgaard, J., Sørensen, J.G., 2007. The influence of developmental stage on cold shock resistance and the ability to cold-harden in Drosophila melanogaster. J. Insect Physiol. 53, 179-186.

Johnson, C.G., 1969. Migration and dispersal of insects by flight. Methuen, London.

Ketterson, E.D., Nolan, V.J., 1976. Geographic variation and its climatic correlates in the sex ratio of eastern-wintering dark-eyed juncos (Junco hyemalis hyemalis). Ecology 57, 679-693

Klaasen, 1996. Metabolic constraints on long-distance migration in birds. Indian J. Exp. Biol. 199, 57-64.

Klok, C.J., Chown, S.L., 1997. Critical thermal limits, temperature tolerance and water balance of a sub-Antarctic caterpillar, Pringleophaga marioni (Lepidoptera: Tineidae). J. Insect Physiol. 43, 685-694.

Klok, C.J., Chown, S.L., 1998. Interactions between desiccation resistance, host-plant contact and the thermal biology of a leaf-dwelling sub-antarctic caterpillar, Embryonopsis halticella (Lepidoptera: Yponomeutidae). J. Insect Physiol. 44, 615-628.

Körtner, G., Pavey, C.R., Geiser, F., 2008. Thermal biology, torpor, and activity in free-living Mulgaras in arid zone Australia during the winter reproductive season. Physiol. Biochem. Zool. 81, 442-451.

Kovac, H., Stabentheiner, A., Hetz, S.K., Petz, M., Crailsheim, K., 2007. Respiration of resting honeybees. J. Insect Physiol. 53, 1250-1261.

Kovac, H., Käfer, H., Stabentheiner, A., Costa, C., 2014. Metabolism and upper thermal limits of Apis mellifera carnica and A. m. ligustica. Apidologie 45, 664-677.

Lehmann, F.O., 2001. The efficiency of aerodynamic force production in Drosophila. Comp. Biochem. Physiol. A 131, 77-88.

Lighton, J.R.B., Fielden, L.J., 1995. Mass scaling of standard metabolism in ticks: a valid case of low metabolic rates in sit-and-wait strategists. Physiol. Zool. 68, 43-62.

Logan, M.L., Huynh, R.K., Precious, R.A., Calsbeek, R.G., 2013. The impact of climate change measured at relevant spatial scales: new hope for tropical lizards. Glob. Chang. Biol. 19, 3093-3102.

Marden, J.H., 2000. Variability in the size, composition, and function of insect flight muscles. Annu. Rev. Physiol. 62, 157-178.

Marra, P.P., Francis, C.M., Mulvihill, R.S., Moore, F.R., 2005. The influence of climate on the timing and rate of spring bird migration. Oecologia 142, 307-315.

Marshall, S.A., 2012. Flies: The Natural History and Diversity of Diptera. Firefly Books, New York.

Mason, L.D., Tomlinson, S., Withers, P.C., Main, B.Y., 2013. Thermal and hygric physiology of Australian burrowing mygalomorph spiders (Aganippe spp.). J. Comp. Physiol. B. $183,71-82$.

Mazerolle, M.J., 2013. AICcmodavg: Model selection and multimodel inference based on (Q)AIC(c). R Package v1.35

McNab, B.K., 1988. Food habits and the basal rate of metabolism in birds. Oecologia 77, 343-349.

Nagy, K.A., Girard, I.A., Brown, T.K., 1999. Energetics of free-ranging mammals, reptiles, and birds. Annu. Rev. Nutr. 19, 247-277.

Nielsen, T.R., 2009. A migration of Eristalis similis (Fallén, 1817) (Diptera, Syrphidae) at Lindesnes, South Norway in 2009. Nor. J. Entomol. 56, 74.

Nilsson, A.L.K., Nilsson, J.Å., Alerstam, T., 2011. Basal metabolic rate and energetic cost of thermoregulation among migratory and resident blue tits. Oikos 20, 1784-1789.

Niven, J.E., Scharlemann, J.P.W., 2005. Do insect metabolic rates at rest and during flight scale with body mass? Biol. Lett. 1, 346-349.

Nyamukondiwa, C., Terblanche, J.S., 2009. Thermal tolerance in adult Mediterranean and Natal fruit flies (Ceratitis capitata and Ceratitis rosa): Effects of age, gender and feeding status. J. Therm. Biol. 34, 406-414.

Pappas, C., Hyde, D., Bowler, K., Loeschcke, V., Sørensen, J.G., 2007. Post-eclosion decline in 'knock-down' thermal resistance and reduced effect of heat hardening in Drosophila melanogaster. Comp. Biochem. Physiol. A 146, 355-359.

Parkash, R., Kalra, B., Sharma, V., 2008. Changes in cuticular lipids, water loss and desiccation resistance in a tropical drosophilid: analysis of variation between and within populations. Fly 2, 189-197.

Penteado, C.H.S., Hebling-Beraldo, M.J.A., 1991. Oxygen consumption related to size and sex in the tropical millipede Psedonannolene tricolor (Diplopoda: Spirostreptida). Comp. Biochem. Physiol. A 98, 265-269.

Radloff, S.E., Hepburn, H.R., Koeniger, G., 2003. Comparison of flight design of Asian honeybee drones. Apidologie 34, 353-358.
Rajagopal, P.K., Bursell, E., 1966. The respiratory metabolism of resting tsetse flies. J. Insect Physiol. 12, 287-297.

Reinhold, K., 1999. Energetically costly behaviour and the evolution of resting metabolic rate in insects. Funct. Ecol. 13, 217-224.

Rogowitz, G.L. Chappell, M.A, 2000. Energy metabolism of Eucalyptus-boring beetles a rest and during locomotion: Gender makes a difference. J. Exp. Biol. 203, 1131-1139.

Rotheray, G.E., Gilbert, F., 2011. The Natural History of Hoverflies. Forrest Text, Cardigan, Ceredigion, UK.

Sarthou, J.-P., Ouin, A., Arrignon, F., Barreau, G., Bouyjou, B., 2005. Landscape parameter explain the distribution and abundance of Episyrphus balteatus (Diptera: Syrphidae). Eur. J. Entomol. 102, 539-545.

Schmidt-Nielsen, K., 1983. Animal Physiology: Adaptation and Environment. Cambridge University Press, New York.

Schneider, F., 1948. Beitrag zur kenntnis der generationsverhältnisse und diapause räuberischer Schwebfliegen (Syrphidae, Diptera). Mitt. Schweiz. Entomol. Ges. 21 249-285.

Shillington, C., 2005. Inter-sexual differences in resting metabolic rates in the Texas tarantula, Aphonopelma anax. Comp. Biochem. Physiol. A 142, 439-445.

Shillington, C., Peterson, C.C., 2002. Energy metabolism of male and female tarantulas (Aphonopelma anax) during locomotion. J. Exp. Biol. 205, 2909-2914.

Skandalis, D.A., Darveau, C.A., 2012. Morphological and physiological idiosyncrasies lead to interindividual variation in flight metabolic rate in worker bumblebees (Bombus impatiens). Physiol. Biochem. Zool. 85, 657-670.

Skov, C., Baktoft, H., Brodersen, J., Brönmark, C., Chapman, B.B., Hansson, L.A., Nilsson, P.A., 2011. Sizing up your enemy: individual predation vulnerability predicts migratory probability. Proc. R. Soc. B 278, 1414-1418.

Speight, M.C.D., 2012. Species accounts of the European Syrphidae (Diptera), 2012. Syrph the Net, the database of European Syrphidae vol. 69. Syrph the Net Publications, Dublin

Stotter, R.L., Terblanche, J.S., 2009. Low temperature tolerance of false codling moth Thaumatotibia leucotreta (Meyrick) (Lepidoptera: Tortricidae) in South Africa. J. Therm. Biol. 34, 320-325

Tanaka, K., Ito, Y., 1982. Decrease in respiratory rate in a wolf spider, Pardosa astrigera (L. Koch), under starvation. Res. Popul. Ecol. 24, 360-374.

Terblanche, JS., Anderson, B.J. 2010. Variation of foraging rate and wing loading, but not resting metabolic rate scaling, of insect pollinators. Naturwissenschaften 97, 775-780.

Terblanche, J.S., Chown, S.L., 2007. The effects of temperature, body mass and feeding on metabolic rate in the tsetse fly Glossina morsitans centralis. Physiol. Entomol. 32 $175-180$

Terblanche, J.S., Klok, C.J., Chown, S.L., 2004. Metabolic rate variation in Glossina pallidipes (Diptera: Glossinidae): gender, ageing and repeatability. J. Insect Physiol. 50, 419-428.

Terblanche, J.S., Klok, C.J., Krafsur, E.S., Chown, S.L., 2006. Phenotypic plasticity and geographic variation in thermal tolerance and water loss of the tsetse Glossina pallidipes (Diptera: Glossinidae): implications for distribution modelling. Am.J.Trop. Med. Hyg. 74, 786-794.

Tomlinson, S., Phillips, R.D., 2012. Metabolic rate, evaporative water loss and field activity in response to temperature in an ichneumonid wasp. J. Zool. 287, 81-90.

Tomlinson, S., Phillips, R.D., 2015. Differences in metabolic rate and evaporative water loss associated with sexual dimorphism in thynnine wasps. J. Insect Physiol. 78, 62-68.

Urquhart, F.A., Urquhart, N.R., 1978. Autumnal migration routes of the eastern population of the monarch butterfly (Danaus p. plexippus L.; Danaidae; Lepidoptera) in North America to the overwintering site in the Neovolcanic Plateau of Mexico. Can J. Zool. 56, 1759-1764.

van Wijk, W.R. 1963. Physics of Plant Environment. North-Holland, Amsterdam.

Waldbauer, G.P., 1978. Phenological adaptation and the polymodal emergence patterns of insects. Evolution of Insect Migration and Diapause. Springer, New York, pp. 127-144.

Watson, P.J., Lighton, J.R.B., 1994. Sexual selection and the energetics of copulatory courtship in the Sierra dome spider, Linyphia litigiosa. Anim. Behav. 48, 615-626.

Weibel, E.R., Bacigalupe, L.D., Schmitt, B., Hoppeler, H., 2004. Allometric scaling of maximal metabolic rate in mammals: muscle aerobic capacity as a determinant factor. Respir. Physiol. Neurobiol. 140, 115-132.

White, C.R., Portugal, S.J., Martin, G.R., Butler, P.J., 2006. Respirometry: anhydrous Drierite equilibrates with carbon dioxide and increases washout times. Physiol. Biochem. Zool. 79, 977-980.

Willmer, P.G., 1988. The role of insect water balance in pollination ecology: Xylocopa and Calotropis. Oecologia 76, 430-438.

Withers, P.C., 1992. Comparative Animal Physiology. Saunders College Publishing, Fort Worth.

Withers, P., 2001. Design, calibration and calculation for flow-through respirometry systems. Aust. J. Zool. 49, 445-461.

Wood, S.N., 2008. Fast stable direct fitting and smoothness selection for generalized additive models. J. R. Stat. Soc. B 70, 495-518.

Woods, H.A., Smith, J.N., 2010. Universal model for water costs of gas exchange by animals and plants. Proc. Natl. Acad. Sci. 107, 8469-8474.

Zachariassen, K.E., 1996. The water conserving physiological compromise of desert insects. Eur. J. Entomol. 93, 359-367.

Zachariassen, K.E., Andersen, J., Maloiy, G.M.O., Kamau, J.M.Z., 1987. Transpiratory wate loss and metabolism of beetles from arid areas in East Africa. Comp. Biochem. Physiol. $86 \mathrm{~A}, 403-408$

Zera, A.J., Brisson, J., 2012. Quantitaive, physiological, and molecular genetics of dispersal/ migration. In: Clobert, J., Baguette, M., Benton, T.G., Bullock, J.M., Ducatez, S. (Eds.) Dispersal Ecology and Evolution. Oxford University Press, Oxford.

Zera, A.J., Harshman, L.G., 2001. The physiology of life history trade-offs in animals. Annu. Rev. Ecol. Syst. 2001, 95-126. 